\title{
Tailings Transport System Design Using Probabilistic Methods
}

\author{
Josh Stowe $^{1} \cdot$ Ian Farrell ${ }^{1} \cdot$ Eric Wingeard ${ }^{1}$ \\ Received: 4 December 2020 / Accepted: 19 March 2021 / Published online: 31 March 2021 \\ (C) The Author(s) 2021
}

\begin{abstract}
Tailings transport system design is generally based on identifying the minimum and maximum process boundary conditions for pump selection and pipeline sizing. The approach is robust and well-proven. However, the approach has the potential to skew selections to operating scenarios that have a very low likelihood of occurring, such as the combination of high solids throughput and low tailings solids concentration. The approach can result in a tailings transport system design that is overly conservative. A probabilistic method-based approach captures the independent variability of design inputs and the combined likelihood of outcomes. This approach identifies the process conditions that have the highest likelihood of occurrence and are most applicable to equipment and pipeline selections. An outline of a probabilistic-based approach to tailings transport system design and the resulting selections is provided in this article. The probabilistic-based system design is compared to the outcomes from the traditional approach. The benefits and challenges to this approach are discussed and recommendations for utilizing this approach for tailings transport system design are provided.
\end{abstract}

Keywords Tailings $\cdot$ Slurry $\cdot$ Pipeline $\cdot$ Design $\cdot$ Probabilistic

\section{Introduction}

Tailings transport system design is typically based on identifying the minimum and maximum process condition bounds for pipe and pump selection. However, it can skew selections to accommodate operating scenarios that, when investigated in detail, have very low likelihood of occurrence (e.g. high throughput, low concentration). This approach can result in a tailings transport system design that is overly conservative.

A probabilistic method-based approach that captures the variability in design inputs and the combined likelihood of outcomes can identify which process conditions have the greatest likelihood of occurrence and are most applicable to equipment and pipeline selections. To evaluate this methodology, a probabilistic-based system design is compared to the outcomes from the typical design approach of minimum and maximum process condition bounds. The findings and challenges with the proposed approach and opportunities for its use in other applications are discussed.

Josh Stowe

Josh.Stowe@PatersonCooke.com

Paterson \& Cooke, Golden, CO, USA

\section{Tailings Slurry Transport System Design}

Generally, tailings slurry transport system design consists of pipe size, material, and equipment selections based on meeting minimum velocity limitations for maintaining particle suspension and predicted pipeline friction losses. The predictions for these system considerations and resulting selections are dependent on the anticipated process conditions and slurry properties such as solids density, solids concentration, particle size distribution and shape, fluid temperature, and rheological behavior. Typically, a tailings slurry transport system design is based on deterministic inputs: minimum and maximum bounded ranges or set values of the key criteria that are treated with equal likelihood when considering design decisions. This approach is robust and well-proven but does not directly consider the likelihood of the extreme bounds of the process condition ranges.

\section{Probabilistic Methods}

Probabilistic methods are intended to capture uncertainty and predict the occurrence of multiple outcomes based on that uncertainty [1]. Design inputs are captured as probability distributions, instead of set values or bounded 
ranges. The design outputs are similarly described in terms of probability distributions to describe the behavior. The output behavior is often referred to as likelihood of occurrence, probability of failure, reliability, or frequency of operation depending on the nature of the engineering analysis being performed. Probabilistic methods rely on the modeling of uncertainty, with a number of methods available from brute force approaches (Monte Carlo) appropriate for more straight-forward engineering analyses or more elegant approaches intended for more complex engineering analyses [1].

\section{System Description}

The tailings transport system used here is an example and has been prepared using different elements from several different operating tailings systems in North America. Similarly, the operating data used to develop probabilistic definitions of the input variables are compilations of data from different operating tailings systems in North America.

\subsection{Design Criteria Summary}

For this example, some inputs to the tailings transport system design are assumed constant, such as the solids density, liquid density, and slurry temperature. The tailings system inputs that are considered variable, for both the general and probabilistic approaches, are the following:

- Solids throughput (metric tonnes per hour, $\mathrm{t} / \mathrm{h}$ )

- Solids concentration by mass (\%m)

- Particle size distribution (PSD).

The process design inputs for the general design approach are summarized in Table 1. Figure 1 shows a graphical representation of the process range definition for the typical transport system design approach, relating the solids throughput and solids concentration ranges to the resulting slurry flow rate range based on Table 1. The upper bound "Max $\mathrm{P}_{150}$ " PSD and lower bound "Min $\mathrm{P}_{150}$ " PSD in Fig. 2 are considered for the typical design approach.

Table 1 Process design inputs

\begin{tabular}{llll}
\hline Process condition & Minimum & Nominal & Maximum \\
\hline Solids throughput $(\mathrm{t} / \mathrm{h})$ & 2794 & 3492 & 4190 \\
Solids concentration by mass $(\% \mathrm{~m})$ & $45 \%$ & $50 \%$ & $55 \%$ \\
Solids density $\left(\mathrm{kg} / \mathrm{m}^{3}\right)$ & 2700 & & \\
Liquid density $\left(\mathrm{kg} / \mathrm{m}^{3}\right)$ & 1000 & & \\
Slurry temperature $\left({ }^{\circ} \mathrm{C}\right)$ & 23 & & \\
\hline
\end{tabular}

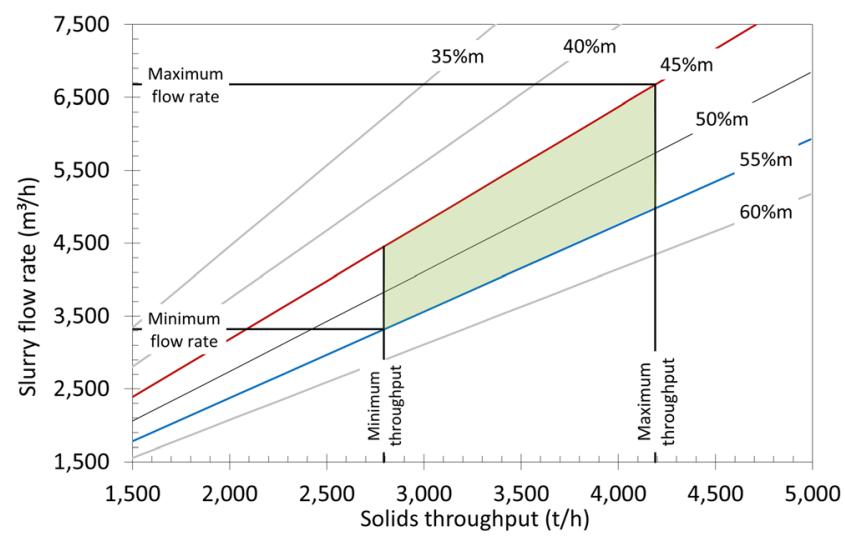

Fig. 1 Typical process range definition

\subsection{Slurry Rheology}

Slurry rheology is a function of solids concentration, and among other properties such as mineralogy, PSD. However, for this investigation, slurry rheology is assumed to be independent of PSD and only a function of solids concentration. The pertinent slurry rheology properties are summarized in Table 2.

\subsection{Pipeline Profile and Selection}

The pipeline profile and pipe selection for this analysis are provided in Fig. 3. The pipe selection is based on the system pressure rating requirements and considers minimum slurry transport velocity limitations.

\section{Typical Design Approach}

Assuming a pumped system, the typical design approach is to define the system requirements (pump head, absorbed power) based on the matrix of process conditions and appropriate pump selection. This matrix is then used to define the installed power required for the pumps in the system, often sized for 1.1

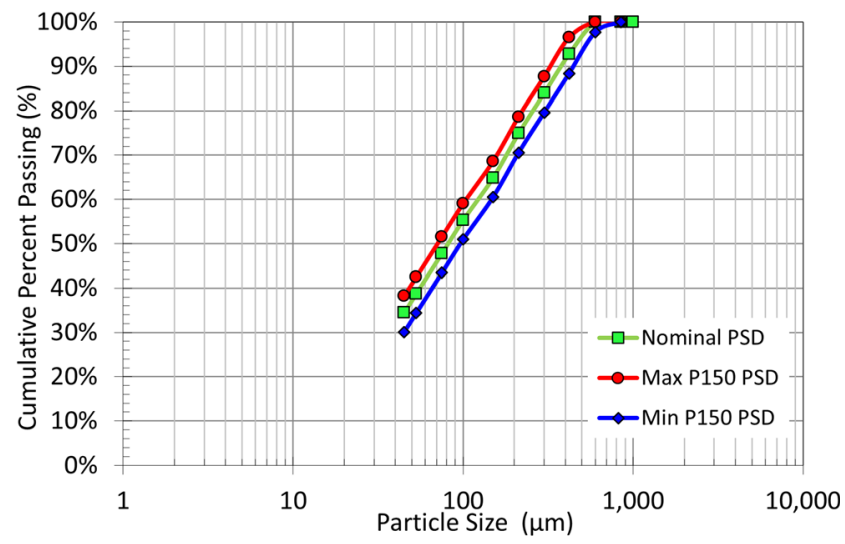

Fig. 2 Particle size distribution range 
Table 2 Pertinent tailings slurry rheology

\begin{tabular}{llll}
\hline Parameter & $45 \% \mathrm{~m}$ & $50 \% \mathrm{~m}$ & $55 \% \mathrm{~m}$ \\
\hline Whole tailings yield stress (Pa) & 0.7 & 2.0 & 5.1 \\
Whole tailings viscosity (mPa·s) $^{\mathrm{a}}$ & 5.9 & 8.2 & 12.0 \\
Carrier fluid viscosity $^{\mathrm{a}}(\mathrm{mPa} \cdot \mathrm{s})$ & 2.1 & 2.6 & 3.2 \\
\hline
\end{tabular}

a $-45 \mu \mathrm{m}$ fraction plus liquid/water component

to 1.2 times the maximum estimated absorbed power to allow for process upset conditions.

Using this approach and the design criteria presented, the tailings transport system requires three centrifugal pumps inseries, each with a $1750 \mathrm{hp}$ motor, to accommodate the system head at the design throughput. The results of the typical design approach and the maximum requirements are summarized in Table 3.

\section{Probabilistic-Based Design}

\subsection{Input Variable Distributions}

The variable inputs identified for the probabilistic model are solids throughput, solids concentration by mass, and tailings PSD. The input probability distributions are built based on operating data from several operating mine sites in North America.

The input data are characterized using statistical analysis to establish each input's probability distribution parameters. The inputs are assumed to be uncorrelated. The input distribution parameters are summarized in Table 4, with the base histograms and resulting probability density functions (PDF) and cumulative distribution functions (CDF) shown in Fig. 4. The PSD source data are based on a single characteristic cumulative percent passing of a

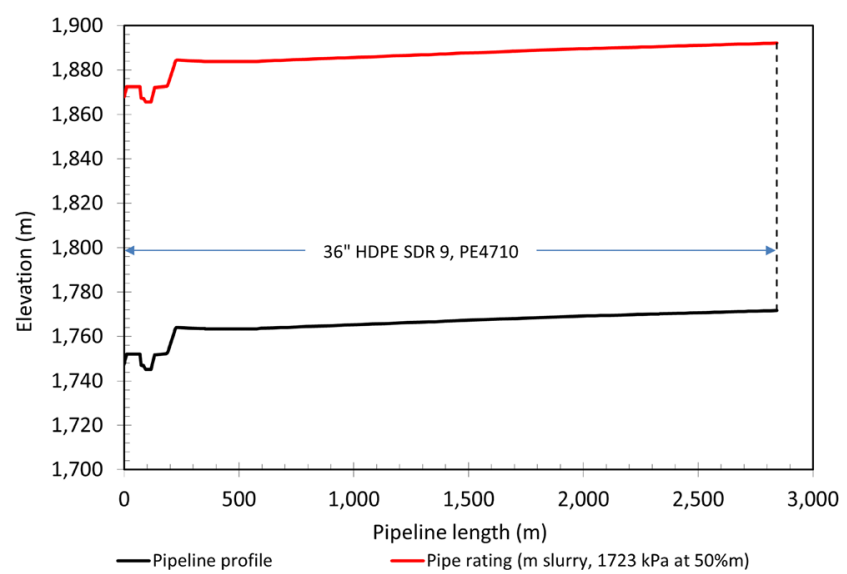

Fig. 3 Pipeline profile and pipe selection
$150 \mu \mathrm{m}$ sieve $\left(\mathrm{P}_{150}\right)$ measurement, with only a limited number of full sieve sets available. Based on the nature of the data, an estimate of the full PSD must be made based on the available $\mathrm{P}_{150}$ measurements. To do so, a base reference tailings PSD is selected from one of the available full sieve sets; see "Nominal PSD" in Fig. 2. The base reference PSD is evaluated and fitting parameters to this base PSD are estimated using a RosinRammler fit $[2,3]$. To estimate the full slurry PSD for a given probabilistic model run based on the source data, described in more detail in the following sections, a full PSD is estimated based on the Rosin-Rammler fit parameters and the $\mathrm{P}_{150}$ size selected from the input variable distribution.

\subsection{Simulation}

The input distributions are used with the Monte Carlo simulations [1] to calculate process scenarios and the required design parameters. A total of 5000 simulations are conducted for this study.

The Monte Carlo simulation technique, in essence, uses randomly generated probabilities, relates those probabilities to the input variable distributions, and then calculates a deterministic outcome based on the randomly selected inputs. This process is repeated numerous times, from hundreds to hundreds of thousands of iterations depending on complexity, to map the outcome distributions behavior.

\subsection{Probabilistic Model Results}

The resulting process scenarios from the simulations are compared to the typical design approach range in Fig. 5. As illustrated in Fig. 5, some probabilistic simulations fall outside of the process criteria range used for the typical design approach.

Similar to the typical design approach, the primary outputs of interest for the probabilistic approach are pump head, pump absorbed power, and motor selection. Much like the definition of the input variables, the output data are characterized by statistical analysis to establish each output variable's probability distribution parameters. The output distribution parameters are summarized in Table 5, with the base histograms and resulting PDF and CDF curves shown in Fig. 6.

It should be noted that the probabilistic model can be used to identify and quantify the likelihood of violating minimum operating velocity requirements. For this particular system, simulations that resulted in operating velocities less than the predicted minimum recommended velocity were flagged and excluded from the output (93 out of the 5000 simulations). 
Table 3 Typical design approach, outcome summary

\begin{tabular}{|c|c|c|}
\hline Parameter & "Max $\mathrm{P}_{150}$ " PSD & "Min $\mathrm{P}_{150} " \mathrm{PSD}$ \\
\hline Solids throughput $(\mathrm{t} / \mathrm{h})$ & 4190 & \\
\hline Solids concentration by mass $(\% \mathrm{~m})$ & $45 \%$ & \\
\hline Slurry flow rate $\left(\mathrm{m}^{3} / \mathrm{h}\right)$ & 6671 & \\
\hline Total pump head (m slurry) & 87 & 84 \\
\hline Pump efficiency & $78 \%$ & $78 \%$ \\
\hline Maximum absorbed power per pump (kW), 3 pumps in-series & 939 (1259 hp) & 898 (1204 hp) \\
\hline Motor selection (hp), including 1.2 FOS & 1,750 & \\
\hline
\end{tabular}

The outcome of the probabilistic approach is summarized in Table 6. The outputs in Table 6 are structured for comparison with those from the typical design approach. Of primary interest is the resulting pump motor selection; Table 5 illustrates that the motor selection changes based on the probability limitations that were used for the basis of selection. The more conservative selection of $1500 \mathrm{hp}$ accommodates up to $99 \%$ of the simulated scenarios based on the probabilistic inputs $(\mathrm{CDF}=0.99, p=$ $0.01)$. For a slightly less conservative and more risktolerant design, the motor selection is $1250 \mathrm{hp}$. This selection accommodates up to $95 \%$ of probable outcomes $(\mathrm{CDF}=0.95, p=0.05)$.

\section{Findings and Discussion}

Table 7 compares the outcomes between the typical design approach and the probabilistic approach. As shown in Table 7, there are potential installed power savings should the probabilistic design approach be adopted in this particular example. Given that there are three pumps in-series, the total savings can range from $750 \mathrm{hp}$ to 1500 $\mathrm{hp}$, and $1500 \mathrm{hp}$ to $3000 \mathrm{hp}$ if a duplicate standby pump train is considered. The extent of installed power savings is dependent on the risk-tolerance of the tailings transport system and how it fits into the overall project risk. The potential reduction in installed pump power will have an effect on the initial capital for the pumps, motors, and associated drives, as well as impact the overall power distribution system design and capital cost. To help illustrate the potential cost benefit, Table 7 includes a high level estimation of potential relative capital costs based on an assumed conceptual level unit rate for the slurry pumps of $\$ 410$ per installed motor horsepower; the costs included are for the pump, drive, and motor only and do not include differential costs for other potentially affected design features such as standby pump train philosophy, electrical infrastructure, pump station footprint requirements, and seal water considerations.

Notably, using the probability distributions presented in Table 5 and Fig. 6, the probability of occurrence for the process condition and maximum absorbed power per pump used in the typical approach is 0.005 (CDF $=$ 0.995). Based on the example presented, there is potential power savings to be realized with only modest changes to the selection criteria and use of a probabilistic approach.

Even in cases where motor power savings cannot be achieved without considerable risk, the probabilistic approach to the design of a tailings transport system is useful to identify the likelihood/probability of operating scenarios that result in operating velocities less than minimum requirements, thus, identifying risk of pipeline blockage; fully map the system response based on the combination of the input probability distributions, which could lead to optimized pump selection, as well as pipe
Table 4 Input variable distribution parameters

\begin{tabular}{|c|c|c|c|c|}
\hline \multirow[t]{2}{*}{ Input } & \multicolumn{2}{|c|}{ Normal distribution } & \multicolumn{2}{|c|}{ Weibull distribution } \\
\hline & $\begin{array}{l}\text { Mean } \\
\mu\end{array}$ & $\begin{array}{l}\text { Std Dev } \\
\sigma\end{array}$ & $\begin{array}{l}\text { Scale } \\
\alpha\end{array}$ & $\begin{array}{l}\text { Shape } \\
\beta\end{array}$ \\
\hline Solids throughput $(\mathrm{t} / \mathrm{h})$ & $\mathrm{n} / \mathrm{a}$ & $\mathrm{n} / \mathrm{a}$ & 3,700 & 9.68 \\
\hline Solids concentration by mass $(\% \mathrm{~m})$ & $\mathrm{n} / \mathrm{a}$ & $\mathrm{n} / \mathrm{a}$ & 0.534 & 25.41 \\
\hline $\mathrm{PSD}, \mathrm{P}_{150}(\%)$ & 0.645 & 0.04 & $\mathrm{n} / \mathrm{a}$ & $\mathrm{n} / \mathrm{a}$ \\
\hline
\end{tabular}


Fig. 4 Input distributions summary

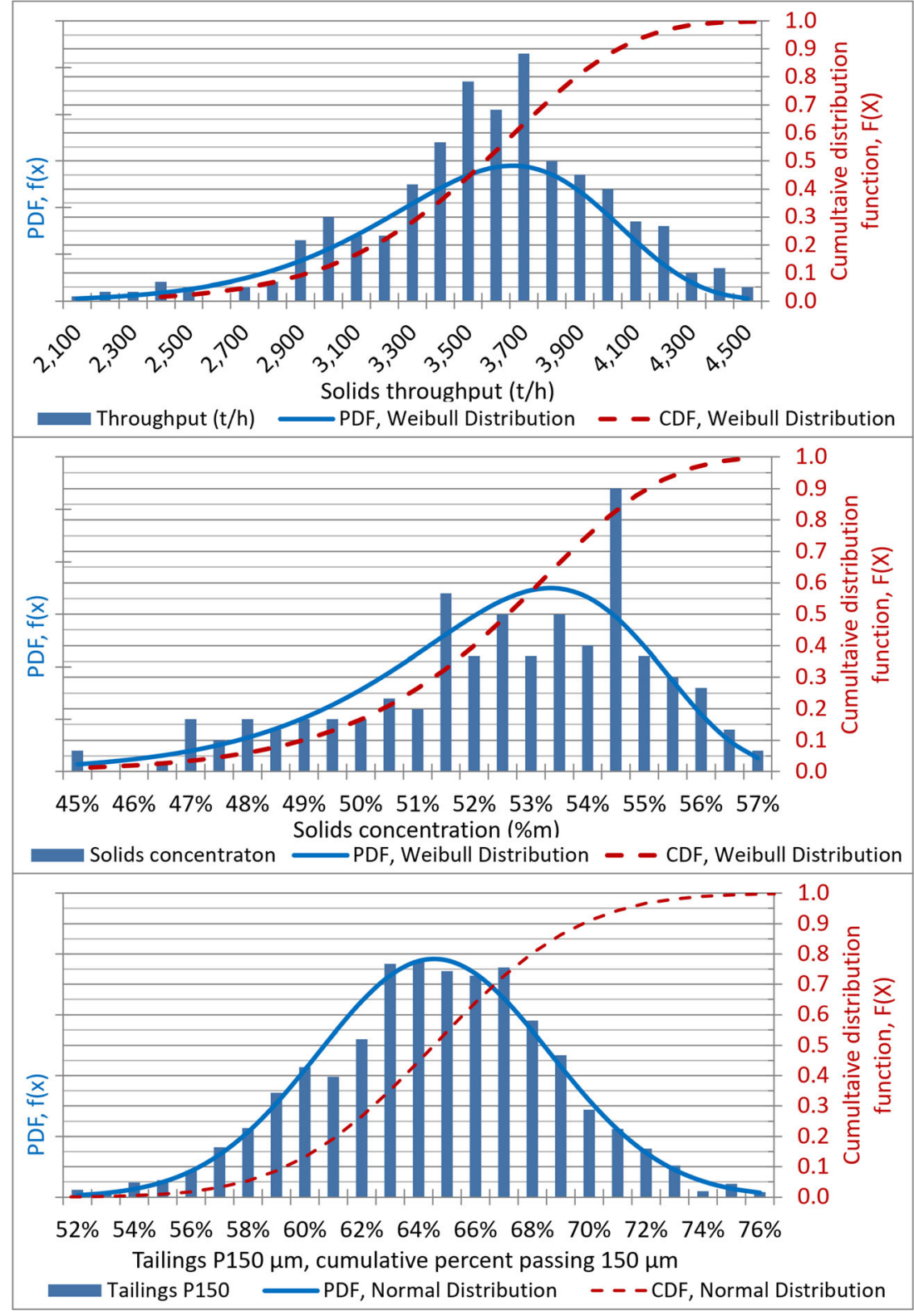

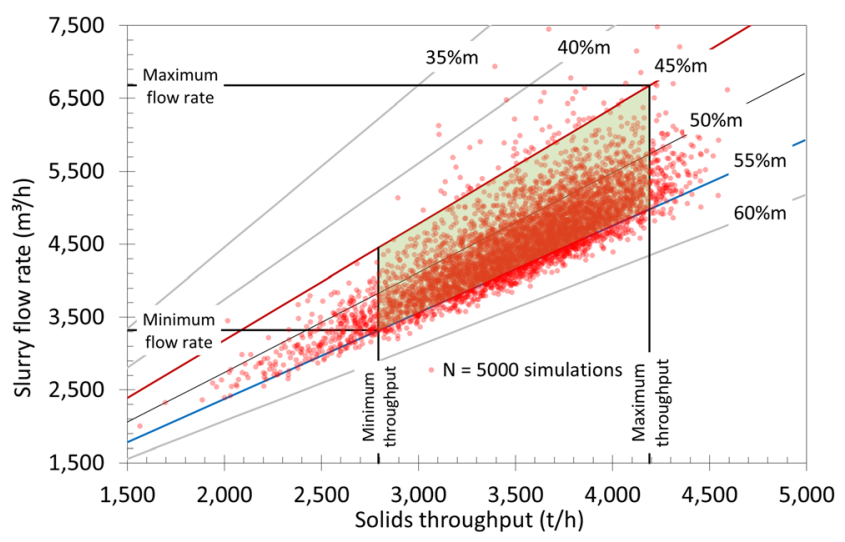

Fig. 5 Process range with probabilistic scenarios size and/or material selection; and identify the likelihood/ probability of at-risk pipeline operations such as unknown slack flow operation or exceeding pipeline pressure rating for unknown worn pipe conditions.

\section{Challenges}

As with any probabilistic-based engineering approach, the output accuracy is dependent on the quality and understanding of the input data and associated probability distribution definitions. Care is required in defining the input distribution parameters to properly capture the behavior of 
Table 5 Output distribution parameters

Fig. 6 Output distributions summary

\begin{tabular}{lll}
\hline Input & \multicolumn{2}{l}{ Gamma distribution } \\
\cline { 2 - 3 } & Shape & Scale \\
& $\alpha$ & $\sigma$ \\
\hline Total pump head (m slurry) & 61.7 & 0.95 \\
Total absorbed power (kW) & 15.1 & 105.05 \\
Absorbed power per pump (kW), 3 pumps in-series & 15.1 & 35.02 \\
\hline
\end{tabular}

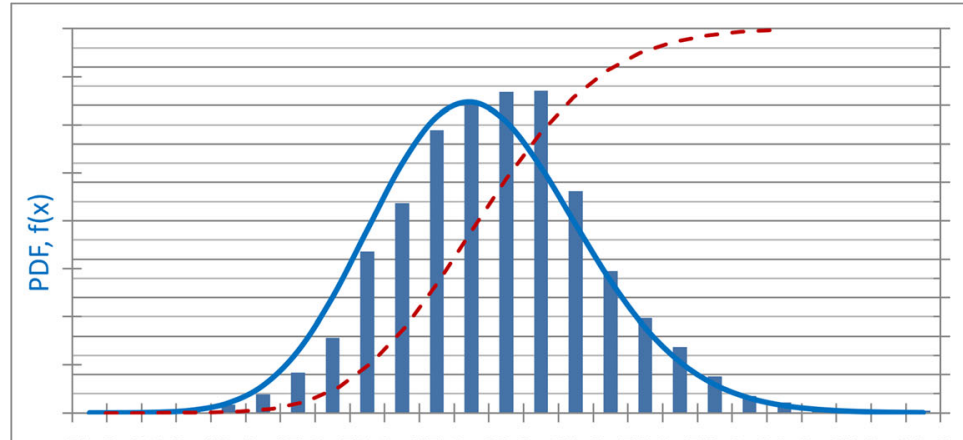

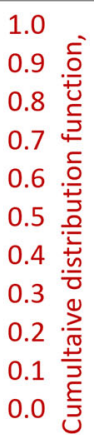

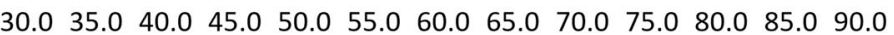

Pump head (m slurry)

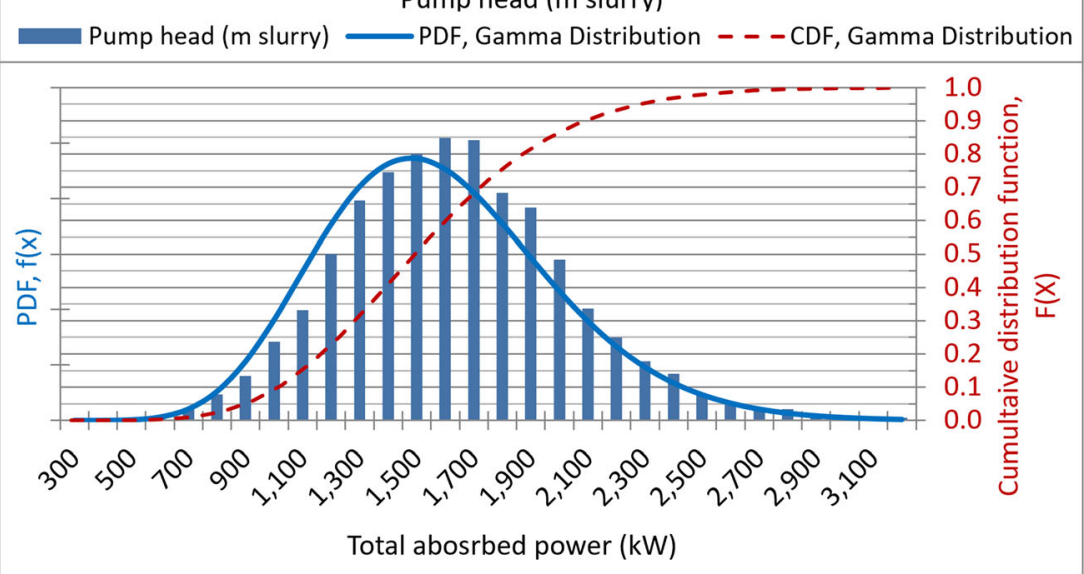

Total abosrbed power (kW) _ PDF, Gamma Distribution - - - CDF, Gamma Distribution

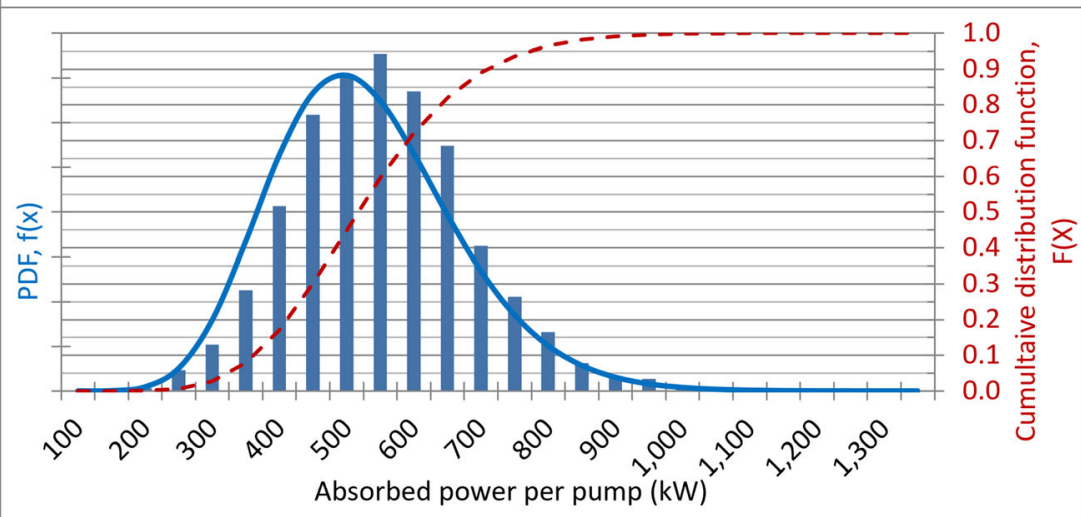

Abs. Power per pump —PDF, Gamma Distribution - - - CDF, Gamma Distribution 
Table 6 Probabilistic design approach, outcome summary

\begin{tabular}{|c|c|c|c|}
\hline Parameter & $\mathrm{CDF}=0.99$ & $\mathrm{CDF}=0.975$ & $\mathrm{CDF}=0.95$ \\
\hline Total pump head (m slurry) & 77 & 74 & 71 \\
\hline $\begin{array}{l}\text { Maximum absorbed power per pump (kW) } 3 \text { pumps } \\
\text { in-series }\end{array}$ & 899 (1205 hp) & 827 (1109 hp) & 771 (1034 hp) \\
\hline Motor selection (hp), including 1.2 FOS & 1500 & 1500 & 1250 \\
\hline
\end{tabular}

Table 7 Comparison of results

\begin{tabular}{lllll}
\hline Parameter & Typical & CDF $=0.99$ & CDF $=0.975$ & CDF $=0.95$ \\
\hline Total pump head (m slurry) & 87 & 77 & 74 & 71 \\
$\begin{array}{l}\text { Maximum absorbed power per } \\
\text { pump (kW) 3 pumps in-series }\end{array}$ & $939(1259 \mathrm{hp})$ & $899(1205 \mathrm{hp})$ & $827(1109 \mathrm{hp})$ & $771(1034 \mathrm{hp})$ \\
$\begin{array}{l}\text { Motor selection (hp), including 1.2 } \\
\quad \text { FOS }\end{array}$ & 1750 & 1500 & 1500 & 1250 \\
\begin{tabular}{l} 
Relative pump costs (USD) \\
\hline
\end{tabular} & Baseline & $-\$ 307,500$ & $-\$ 307,500$ & $-\$ 615,000$ \\
\hline
\end{tabular}

the supporting data. This is particularly challenging for green fields projects that have no defined operating data from which to work. In that case, parallels to similar operations and flow sheets must be drawn to be able to adopt the probabilistic approach.

Designing a tailings slurry transport system to ensure reliable operation for all possible envisioned operating scenarios is certainly an option. The typical design approach, provided the bounds are properly set, results in a design that is conservative. However, conservative design and reduced risk comes at the cost of the infrastructure required to accommodate the design criteria. If a probabilistic approach to a tailings slurry transport system design is adopted, the risk associated with selecting the probability limits from which to base equipment selections must be carefully weighed.

\section{Potential Opportunities}

Quantifying the sensitivity of the probabilistic model outcomes to the input variable distributions, for this example model and those developed in the future, is a reasonable evolution of the proposed design approach. Similarly, variability in the process inputs that are assumed constant for this analysis, such as tailings slurry rheology and solids density, can be defined and considered part of the probabilistic approach to tailings transport system design. The variability in pipeline discharge location as defined by a deposition plan and tailings facility requirements could also be incorporated into the probabilistic model to fully map the system requirements to be used for pump and pipeline selection.

The authors believe that there are other potential applications to the probabilistic-based design approach beyond slurry pipeline design, notably: evaluating hydrocyclone selections, operating parameters and performance metrics, and evaluating the likelihood of achieving operating targets; thickener sizing and likelihood of achieving performance requirements; and computational fluid dynamic models used to troubleshoot process equipment.

More sophisticated simulation techniques are available and reduce the computational time required by the Monte Carlo technique. These techniques should be investigated if complex deterministic models are computationally cumbersome.

\section{Declarations}

Conflict of Interest The authors declare no competing interests.

Open Access This article is licensed under a Creative Commons Attribution 4.0 International License, which permits use, sharing, adaptation, distribution and reproduction in any medium or format, as long as you give appropriate credit to the original author(s) and the source, provide a link to the Creative Commons licence, and indicate if changes were made. The images or other third party material in this article are included in the article's Creative Commons licence, unless indicated otherwise in a credit line to the material. If material is not included in the article's Creative Commons licence and your intended use is not permitted by statutory regulation or exceeds the permitted use, you will need to obtain 
permission directly from the copyright holder. To view a copy of this licence, visit http://creativecommons.org/licenses/by/4.0/.

\section{References}

1. Haldar A, Mahadevan S (2000) Probability, reliability, and statistical methods in engineering design. John Wiley \& Sons, Inc., New York
2. Napier-Munn TJ, Morrell S, Morrison RD, Kojovic T (2005) Mineral comminution circuits, their operation and optimisation. Julius Kruttschnitt Mineral Research Centre, Australia

3. Rosin P, Rammler E (1933) The laws governing the fineness of powdered coal. J Inst Fuel 7:29-36

Publisher's Note Springer Nature remains neutral with regard to jurisdictional claims in published maps and institutional affiliations. 